\title{
Short communication: Meta-analysis on therapy of bovine endometritis with prostaglandin $F_{2 \alpha}-$ An update
}

\author{
P. Haimerl, W. Heuwieser, ${ }^{1}$ and S. Arlt \\ Clinic for Animal Reproduction, Faculty of Veterinary Medicine, Freie Universität Berlin, Koenigsweg 65, 14163 Berlin, Germany
}

\begin{abstract}
The objective of the study was to update a prior meta-analysis on the efficacy of the treatment of bovine endometritis with $\mathrm{PGF}_{2 \alpha}$. Clinical endometritis in cattle is defined as the presence of a purulent or mucopurulent vaginal discharge after 20 or $26 \mathrm{~d}$, respectively, postpartum. Although the prevalence and impact of this disease are well known, the questions of whether and how to treat endometritis are still controversially discussed. Hence, to ensure timeliness of scientific results, we updated an existing meta-analysis published in 2013 that showed no treatment effect of $\mathrm{PGF}_{2 \alpha}$ in cases of bovine endometritis. As in the prior meta-analysis, a comprehensive literature search was conducted. After applying specific inclusion and exclusion criteria, 3 trials remained that could be added to the 6 trials in the initial meta-analysis. Data for each trial were analyzed using the meta-analysis software Review Manager (version 5.3; The Nordic Cochrane Centre, Copenhagen, Denmark). Estimated effect sizes of $\mathrm{PGF}_{2 \alpha}$ were calculated on calving to first service interval (CFSI) and calving to conception interval (CCI). As revealed by the initial meta-analysis, $\mathrm{PGF}_{2 \alpha}$ treatment still had no effect on both reproductive parameters. Heterogeneity remained substantial for CFSI and CCI and even increased for CCI compared with the initial meta-analysis. Subgroup analysis, however, did not reveal a source of heterogeneity. In updating the meta-analysis, publication bias for trials reporting CCI became even more pronounced, suggesting that studies with higher standard error (i.e., usually smaller studies) that reported a prolonging effect on CCI after a $\mathrm{PGF}_{2 \alpha}$ treatment were less likely to be published. Finally, although the number of trials published on the chosen topic and their comparability are still limited, this update of our meta-analysis now provides results that are based on approximately twice the number of included cows. The overall outcome, however, has not
\end{abstract}

Received April 17, 2018.

Accepted July 3, 2018.

${ }^{1}$ Corresponding author: w.heuwieser@fu-berlin.de substantially changed and a positive effect of a $\mathrm{PGF}_{2 \alpha}$ treatment in case of clinical endometritis could not be shown. Therefore, we do not recommend a treatment of bovine endometritis with $\mathrm{PGF}_{2 \alpha}$ as a means to improve reproductive performance.

Key words: meta-analysis, endometritis, prostaglandin $\mathrm{F}_{2 \alpha}$, update, dairy cow

\section{Short Communication}

Clinical endometritis in cattle is defined as the presence of a purulent (>50\% pus) or mucopurulent (approximately $50 \%$ pus, $50 \%$ mucus) vaginal discharge detectable more than 20 or 26 d, respectively, postpartum (Sheldon et al., 2006). Because there is no cytological evidence of endometritis in some cows with abnormal vaginal discharge, the term "purulent vaginal discharge" has been introduced (Dubuc et al., 2010).

High prevalence and severe negative consequences of clinical endometritis are well known (Sheldon et al., 2009; de Boer et al., 2014) and treatment may be indicated to cure the disease and restore fertility, even though affected cows do not show any systemic signs of illness (Sheldon et al., 2006). Whether and how to treat endometritis, however, remains controversial (Arlt et al., 2009; Dubuc et al., 2011). This controversy exists because of high self-cure rates (Dubuc et al., 2011; Giuliodori et al., 2017) and several treatment options that, in part, showed unsatisfactory treatment outcomes (Madoz et al., 2017). A good number of studies have investigated the treatment outcome after a $\mathrm{PGF}_{2 \alpha}$ application (Haimerl et al., 2012). Results, however, are contradictory (Mejía and Lacau-Mengido, 2005; Hirsbrunner et al., 2006; Kaufmann et al., 2010; Dubuc et al., 2011). Therefore, we conducted a systematic literature search to analyze the overall treatment effect of $\mathrm{PGF}_{2 \alpha}$ on reproductive performance by means of a meta-analysis (Haimerl et al., 2013). Meta-analyses are considered to provide the highest evidence, although, due to their nature, the results are always retrospective and may already be outdated at time of their publication (Arlt and Heuwieser, 2005). Hence, it should be common practice to update meta-analyses regu- 
larly when new research results are available, as recommended and performed by the Cochrane Collaboration in human medicine (Cochrane Collaboration, 2018). Therefore, the objective of this study was to update a prior meta-analysis on the efficacy of the treatment of bovine endometritis with $\mathrm{PGF}_{2 \alpha}$ (Haimerl et al., 2013). Specifically, we hypothesized an increase in randomized, controlled studies eligible for meta-analytical assessment. A second objective was to provide an example and format for such an update and stimulate similar initiatives for other relevant topics. The review approach and statistical methods used were similar to those of the original publication (Haimerl et al., 2013) with minor modifications.

A systematic literature search was conducted on March 2, 2017, and, to ensure currentness, rechecked on February 21, 2018. With the subject heading "endometritis AND cattle AND prostaglandin" we searched the databases PubMed (http://www.pubmed.gov) and CAB Abstracts (http://dbis.ur.de/warpto.php?bib_id=fub \&color $=1 \&$ ocolor $=32 \&$ titel_id $=6897 \& u r l=h t t p \% 3 \mathrm{~A}$ \%2F\%2Fovidsp.ovid.com\%2Fovidweb.cgi\%3FT\%3DJS \%26NEWS\%3Dn\%26CSC\%3DY\%26PAGE\%3Dmain $\% 26 \mathrm{D} \% 3 \mathrm{Dcabd}$ ) to identify literature related to the treatment of endometritis with prostaglandin in dairy cattle published after August 4, 2010 (i.e., the day of the literature search of the initial meta-analysis). To also include publications potentially indexed with delay, we repeated the originally conducted literature search, covering the same time span as the prior meta-analysis.

The modifications regarding the used databases and search engines result from the renaming of Animal Production to CAB Abstracts. Furthermore, the database Medline is now included in PubMed, whereas Vetseek discontinued operation. In contrast to the initial literature search, we exclusively used the subject heading "endometritis AND cattle AND prostaglandin," and decided against the application of "endometritis AND cattle." The prior literature search and a screening of the findings in the course of the actual search revealed that additionally using the subject heading "endometritis AND cattle" did not yield any additional eligible publications.

Inclusion and exclusion criteria were identical to those applied in the first meta-analysis (Figure 1). Retrieval and management of references were performed with Endnote (version X4 for Windows, Thomson Reuters, New York, NY). Conference proceedings were excluded but checked for the potential to offer relevant data by contacting the authors. Authors were also contacted when eligible publications were lacking relevant data. Data for each eligible trial were extracted and analyzed using meta-analysis software (Review Manager, Ver- sion 5.3. Copenhagen: The Nordic Cochrane Centre; Cochrane Collaboration, 2014).

Estimated effect sizes of $\mathrm{PGF}_{2 \alpha}$ were calculated on calving to first service interval (CFSI) and calving to conception interval (CCI), applying the effect size method (Hedges and Olkin, 1985). Effect sizes were calculated for each trial. In addition, an overall effect size, weighted by sample size, was calculated. Because the extracted variables were continuous, a weighted mean difference and 95\% CI were calculated for each trial outcome (Hedges and Olkin, 1985). Variation in experiment-level effect size was assessed with a $\chi^{2}$ test for heterogeneity (Duffield et al., 2008).

Degree of heterogeneity of results among trials was quantified using the $I^{2}$ statistic (Higgins et al., 2003). As significant heterogeneity was found, results were reported using the random effects model and potential sources of heterogeneity were sought by subgroup analysis. Subgroups were formed according to randomization procedure (i.e., conducted vs. not conducted or reported).

To examine whether large-weight studies had an exceptional impact on the overall effect size, a sensitivity analysis was performed considering the effect of a $\mathrm{PGF}_{2 \alpha}$ treatment on CFSI and CCI by eliminating the studies with the largest weights one by one.

Forest plots were used to visually display the estimated effect size (Z), 95\% CI, and study weights. The presence of publication bias was investigated graphically using funnel plots, in which the size of effect for each treatment and control group comparison was plotted against its standard error and the resulting plot observed for deficiencies in predicted funnel shape.

The literature search revealed 105 (PubMed, 6; CAB Abstracts, 99) newly indexed articles published through August 4, 2010. Elimination of doublets led to 75 articles that were eligible for further analysis. However, application of inclusion and exclusion criteria showed that none of those publications met our inclusion criteria. A total of 94 articles published between August 5, 2010, and February 21, 2018, were retrieved. Application of preset exclusion and inclusion criteria on those 94 publications can be retraced in Figure 1. The exclusion of publications adhered to the following hierarchy: exclusion of duplicates; exclusion of review articles, $\mathrm{PhD}$ theses, and conference proceedings; exclusion due to other preset criteria (i.e., studies not focusing on treatment, studies using only concomitant or other treatments, and those focusing on metritis or subclinical endometritis); and exclusion of further offtopic publications.

Finally, only 3 trials (Dubuc et al., 2011; Giuliodori et al., 2017; Borchardt et al., 2018) offering data on 


\section{Literature search}

94 publications identified by systematic database search (PubMed 30; CAB 61) \& hand search $(\mathrm{n}=3)$

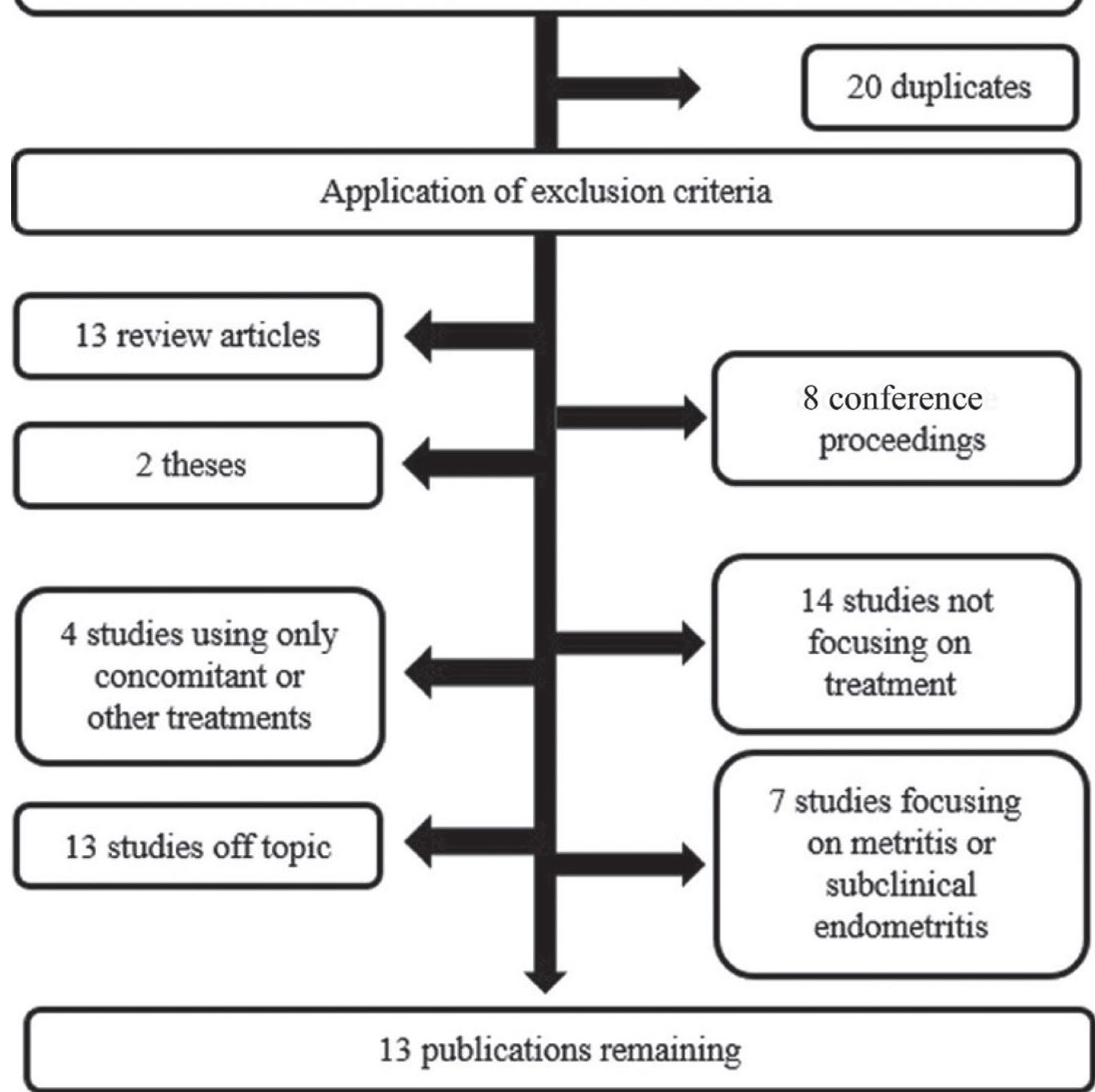

Application of inclusion criteria

Figure 1. Publications on prostaglandin treatment of endometritis in dairy cows retrieved on March 2, 2017, and rechecked on February 21, 2018, and systematically evaluated after applying preset exclusion criteria. Two theses were excluded because they were also published as journal articles; and 14 studies were excluded because they focused on etiological, microbiological, or nutritional results, clinical symptoms, or diagnostic procedures instead of treatment. The inclusion criteria were existence of an untreated control group and calculation of median and standard deviation of calving to first service interval (CFSI) and calving to conception interval (CCI). 
either CFSI alone or both CFSI and CCI could be added to the 6 trials used in the initial meta-analytic investigation, showing the persisting dearth of comparable clinical trials on this topic and rejecting our first hypothesis.

Compared with the previous meta-analysis with 6 trials in 5 publications comprising 2,596 cows, the actual analysis to assess the effect of a $\mathrm{PGF}_{2 \alpha}$ treatment in case of clinical endometritis on CCI was based on 9 trials in 8 eligible studies $(5,563$ cows $)$. Because 2 of those trials did not report CFSI, only 7 trials in 6 studies $(4,788$ cows $)$ were available to assess the effect of a $\mathrm{PGF}_{2 \alpha}$ treatment on CFSI compared with the initial meta-analysis of 5 trials in 4 publications $(2,510$ cows). A numerical comparison of the prior and the actual meta-analysis is shown in Table 1. Statistical significance was considered at $P<0.05$.

The impact of the newly included trials by Borchardt et al. (2018) and Dubuc et al. (2011) on the outcome of the previous meta-analysis is visualized in Figure 2. According to the initial meta-analysis, $\mathrm{PGF}_{2 \alpha}$ treatment led to a significant effect $(\mathrm{Z}=2.12 ; P=0.03)$ on CFSI, meaning that treatment caused a prolongation of this interval, which can be interpreted as a negative clinical effect. The updated forest plot (lower pane) still reveals a prolongation of CFSI by $\mathrm{PGF}_{2 \alpha}$ treatment. However, this effect size was not significant $(\mathrm{Z}=1.65 ; P=0.10)$.
Concerning the effect of $\mathrm{PGF}_{2 \alpha}$ on CCI, a comparison of the findings of the initial and updated meta-analyses (Figure 3) revealed a reduction in effect size (from 12.35 to 4.93). Effect size in the updated meta-analysis, however, remained significant $(P<0.00001)$ and favored the untreated control group, which again supports our null hypothesis. Data helping to explain why $\mathrm{PGF}_{2 \alpha}$ fails to improve reproductive performance are rare. Sheldon et al. (2009) suspected that subclinical endometritis persists even after clinical signs of endometritis have resolved. Subclinical endometritis is widely agreed to reduce fertility, according to a traditional review by Wagener et al. (2017). Data on $\mathrm{PGF}_{2 \alpha}$ and its impact on clinical cure considering animal welfare are contradictory (Feldmann et al., 2005; Dubuc et al., 2011; Giuliodori et al., 2017). One of the major benefits of $\mathrm{PGF}_{2 \alpha}$ is thought to result from luteolysis (Kasimanickam et al., 2005), so the question arises whether a responsive corpus luteum is necessary for $\mathrm{PGF}_{2 \alpha}$ to be effective. With regard to metritic cows, for example, McDougall et al. (2013) found comparable reproductive performance for $\mathrm{PGF}_{2 \alpha}$ treatment and antibiotic treatment, provided that the treated cows had a corpus luteum. Similarly, the study by LeBlanc (2003) found a reduction in pregnancy rate when $\mathrm{PGF}_{2 \alpha}$ was applied to cows without a corpus luteum. Other endometritis studies, however, failed to show such effects (Feldmann

Table 1. Comparison of 2 meta-analytic evaluations (literature search in August 2010 and February 2018) of the effect of $\mathrm{PGF}_{2 \alpha}$ on reproductive performance ${ }^{1}$

\begin{tabular}{lcc}
\hline & \multicolumn{2}{c}{ Literature search } \\
\cline { 2 - 3 } Parameter & August 2010 & February 2018 \\
\hline Calving to first service interval & 5 & 7 \\
Number of trials & 2,510 & 4,788 \\
Number of cows & $2.12(P=0.03)$ & $1.65(P=0.10)$ \\
Effect $(Z)$ & 60.88 & 73.22 \\
Heterogeneity & $100 \%$ & $100 \%$ \\
$\tau^{2}$ & $1,898.34$ & $2,423.51$ \\
$I^{2}$ & $4(P<0.00001)$ & $6(P<0.00001)$ \\
$\chi^{2}$ & $0.59,15.40 / 8.00$ & $-1.07,12.32 / 5.62$ \\
df & & No treatment effect \\
$95 \%$ CI/MD & & \\
Conclusion & 6 & 9 \\
& 2,596 & 5,563 \\
Calving to conception interval & $12.35(P<0.00001)$ & $4.93(P<0.00001)$ \\
Number of trials & & \\
Number of cows & 7.02 & 24.20 \\
Effect $(Z)$ & $87 \%$ & $94 \%$ \\
Heterogeneity & 37.83 & 127.11 \\
$\tau^{2}$ & $5(P<0.00001)$ & $8(P<0.00001)$ \\
$I^{2}$ & $16.41,22.61 / 19.51$ & $6.49,15.08 / 10.79$ \\
$\chi^{2}$ & Effect favoring control group & Effect favoring control group \\
df & & \\
$95 \%$ CI/MD & Concing control group & \\
Conclusion & & \\
\hline
\end{tabular}

${ }^{1}$ Summary of effect sizes (Z), 95\% CI, mean differences (MD), between-studies variance $\left(\tau^{2}\right)$, ratio of true heterogeneity to total observed variation $\left(I^{2}\right), \chi^{2}$ and expected variation (df), and $P$-values for each outcome are contrasted. 


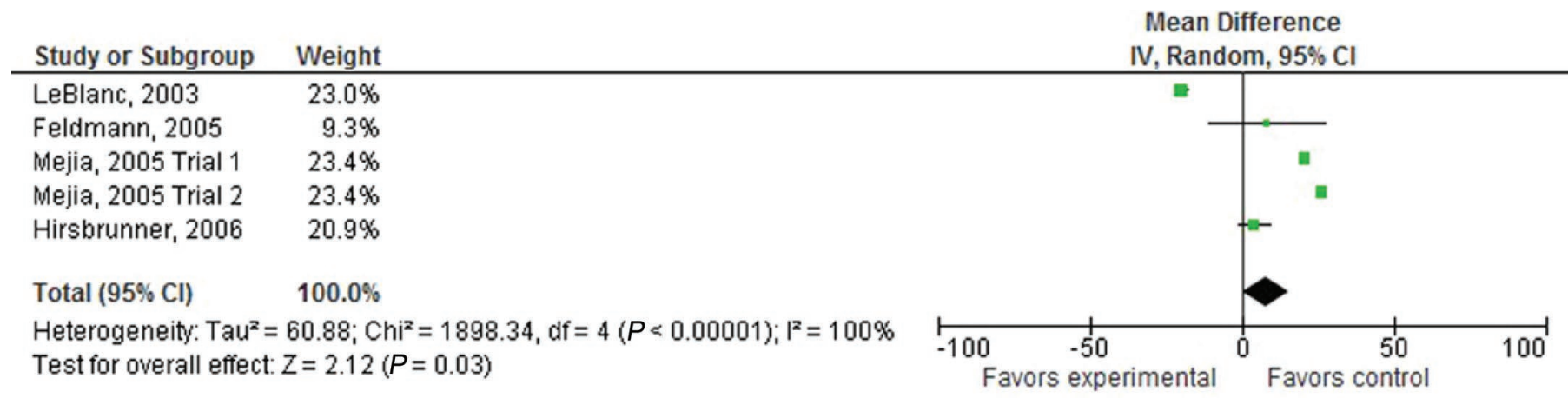

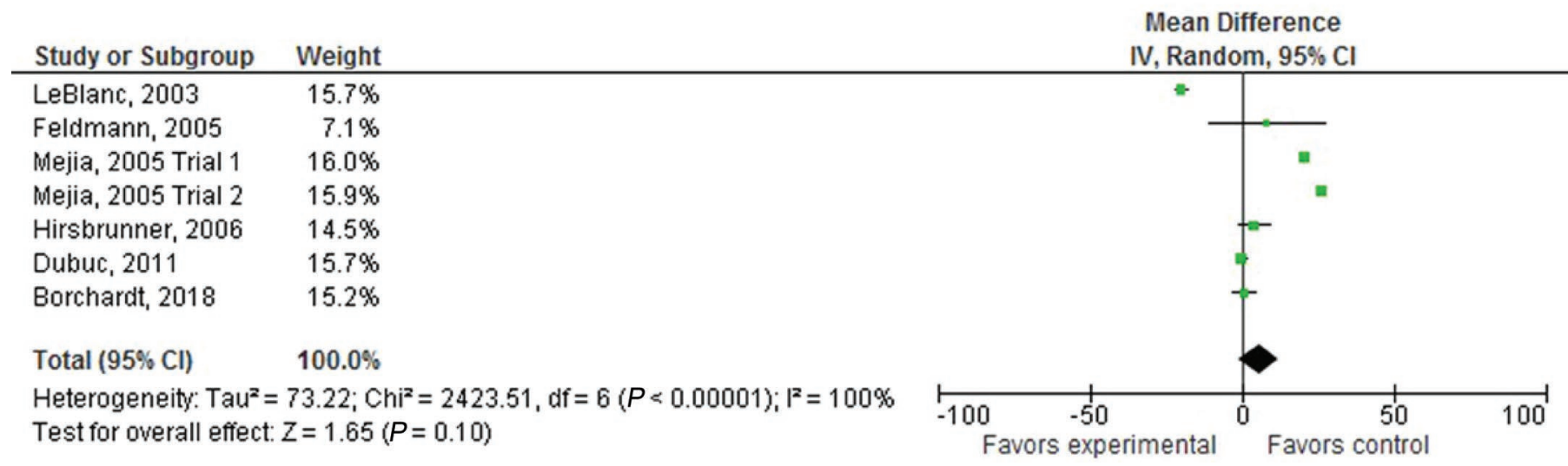

Figure 2. Forest plot of the effect of $\mathrm{PGF}_{2 \alpha}$ on calving to first service interval in dairy cows suffering from clinical endometritis. Comparison of the outcome of the initial meta-analysis (Haimerl et al., 2013; $\mathrm{n}=5$, top) and the updated meta-analysis ( $\mathrm{n}=7$, bottom). Whereas RANDOM describes the analysis model applied, inverse variance (IV) refers to the statistical method applied. Each square represents the mean effect size for that trial. The upper and lower limit of the line connected to the square represents the upper and lower limits of the $95 \%$ CI for the effect size. The size of the square reflects the relative weighting of the trial to the overall effect size estimate, with larger squares representing greater weight. The diamond at the bottom represents the $95 \%$ CI for the overall estimate (Z). The solid vertical line represents a mean difference of zero or no effect. Squares located on the left side of this line represent studies showing an effect in the group treated with PGF ${ }_{2 \alpha}$, whereas squares located on the right side of this line indicate an effect found in the control group. Study or subgroup refers to the first author and year of the publication. Heterogeneity is quantified by between-studies variance $\left(\mathrm{Tau}^{2}\right)$, ratio of true heterogeneity to total observed variation $\left(I^{2}\right), \mathrm{Chi}^{2}$ and expected variation (df), and the respective $P$-values. Color version available online.

et al., 2005; Dubuc et al., 2011). Treatment efficacy of both $\mathrm{PGF}_{2 \alpha}$ and antibiotic drugs considering cyclicity should be systematically investigated. For 4 (CFSI) and 5 (CCI) trials, confidence intervals including zero could be found, indicating no effect of $\mathrm{PGF}_{2 \alpha}$ treatment in case of clinical endometritis. Interestingly, all 3 newly included trials showed such an overlap with the "no effect" line.

Heterogeneity remained substantial for CFSI $\left(\chi^{2}=\right.$ $\left.2,423.51, \mathrm{df}=6, P<0.00001, I^{2}=100 \%\right)$ and CCI $\left(\chi^{2}=127.11, \mathrm{df}=7, P<0.00001, I^{2}=94 \%\right)$ and even increased for CCI compared with the initial meta-analysis $\left(\chi^{2}=37.38, \mathrm{df}=5, P<0.00001, I^{2}=87 \%\right)$. The high values of $I^{2}(>50 \%)$ especially indicate substantial inconsistency of the results between the trials (Duffield et al., 2008); $\tau^{2}$ refers to the variance of the true effect sizes or between-study variance, whereas $I^{2}$ describes the percentage of total variation across studies that is due to heterogeneity rather than chance. Especially with regard to CFSI, the 95\% CI of individual values (based on SD) varied considerably between studies and did not always overlap. This provides further evidence of medium to high heterogeneity between the studies. Therefore, random effects models were applied and sources of heterogeneity were explored through subgroup analysis. Subgroup analysis comparing randomized and nonrandomized studies revealed similar results as in the prior meta-analysis. Subgroup differences were shown for both CFSI $\left(\chi^{2}=15.88\right.$, df $=1, P<0.0001$, $\left.I^{2}=93.7 \%\right)$ and CCI $\left(\chi^{2}=11.93, \mathrm{df}=1, P=0.0006\right.$, $\left.I^{2}=91.6 \%\right)$. Both the nonrandomized and randomized trials, however, displayed significant heterogeneity among themselves (CFSI: nonrandomized: $\tau^{2}=16.10$, $\chi^{2}=477.32, \mathrm{df}=1, P<0.00001, I^{2}=100 \%$; randomized: $\tau^{2}=151.41, \chi^{2}=213.27, \mathrm{df}=4, P<0.00001$, $I^{2}=98 \%$; CCI: nonrandomized: $\tau^{2}=0.63, \chi^{2}=3.66$, 
$\mathrm{df}=1, P=0.06, I^{2}=73 \%$; randomized: $\tau^{2}=231.60$, $\left.\chi^{2}=67.12, \mathrm{df}=6, P<0.00001, I^{2}=91 \%\right)$. Hence, we might hypothesize that the heterogeneity found in both subgroups has different sources that cannot-to date - be specified to a greater extent because of the limited number of eligible trials.

To test the robustness of the meta-analytic outcome, we performed a sensitivity analysis. As in the prior meta-analytic investigation, it could be shown that the exclusion of the 2 trials that were attributed high weights (18.8\% each) and showed consistently outlying results (Mejía and Lacau-Mengido, 2005) did not reduce the heterogeneity of either outcome $\left(\tau^{2}=151.41\right.$, $\chi^{2}=213.27, \mathrm{df}=4, P<0.00001, I^{2}=98 \%$ for CFSI; $\tau^{2}=231.60, \chi^{2}=67.12, \mathrm{df}=6, P<0.00001, I^{2}=91 \%$ for CCI). This finding is not surprising because those 2 trials were also the ones with the highest weight in the prior meta-analysis. In contrast to the partly significant effect sizes (CFSI: $\mathrm{Z}=1.65, P=0.10$; CCI: $\mathrm{Z}$ $=4.93, P<0.00001)$ favoring the control group before conducting sensitivity analysis, omitting those 2 trials resulted in a numerical improvement after $\mathrm{PGF}_{2 \alpha}$ treatment (CFSI: $\mathrm{Z}=-0.38, P=0.7$; CCI: $\mathrm{Z}=-0.06, P=$ $0.95)$ and a reduction of the variance (CFSI: -2.22 vs. 5.62; CCI: 0.39 vs. 10.79). These findings underline the strong influence that single trials can have on a metaanalytic outcome. As done in many meta-analytical assessments and also conducted by the software used in the present study, the weight assigned to a single trial is based on the included sample size, rather than further

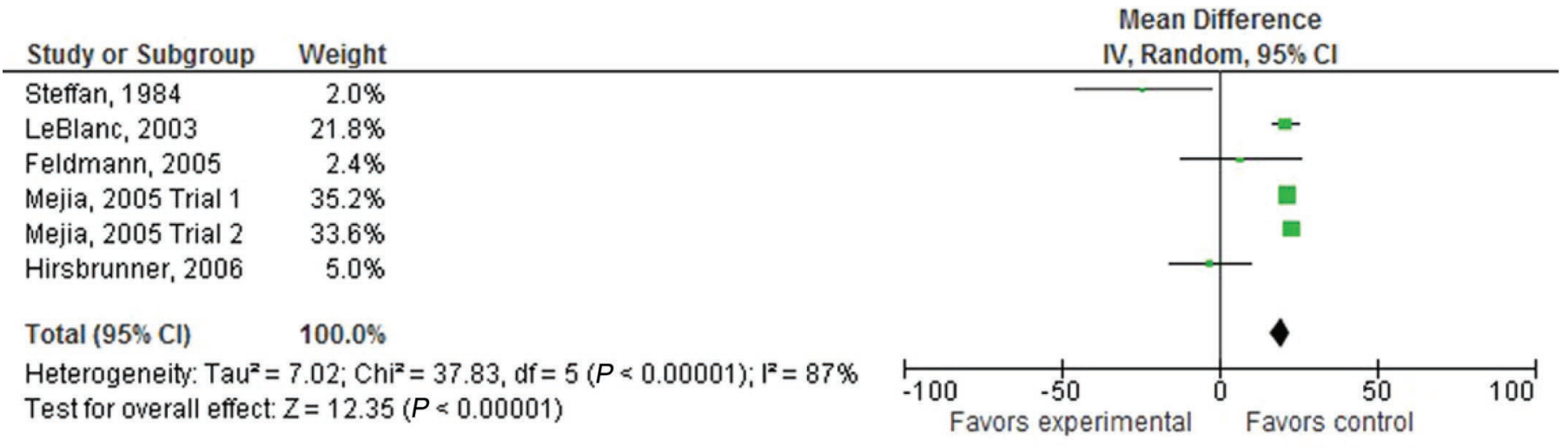

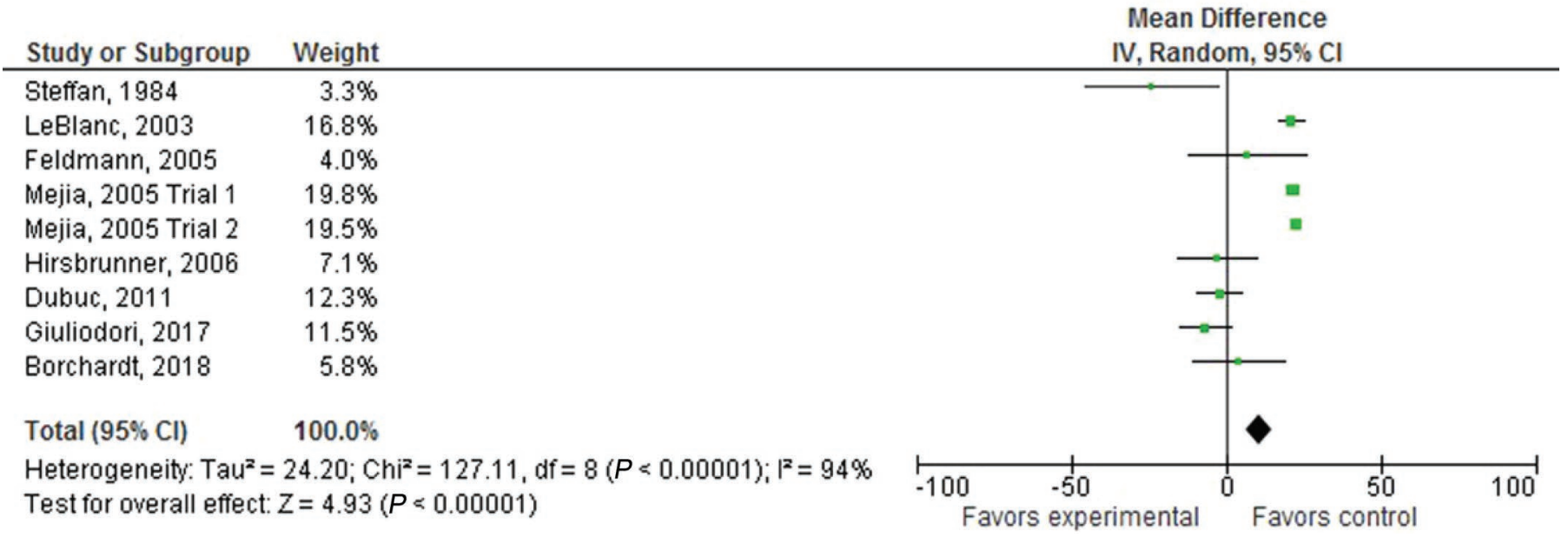

Figure 3. Forest plot of the effect of $\mathrm{PGF}_{2 \alpha}$ on calving to conception interval in dairy cows suffering from clinical endometritis. Comparison of the outcome of the initial meta-analysis (Haimerl et al., 2013; $\mathrm{n}=6$, top) and the updated meta-analysis ( $\mathrm{n}=9$, bottom). Whereas RANDOM describes the analysis model applied, inverse variance (IV) refers to the statistical method applied. Each square represents the mean effect size for that trial. The upper and lower limit of the line connected to the square represents the upper and lower limits of the $95 \%$ CI for the effect size. The size of the square reflects the relative weighting of the trial to the overall effect size estimate, with larger squares representing greater weight. The diamond at the bottom represents the $95 \% \mathrm{CI}$ for the overall estimate $(\mathrm{Z})$. The solid vertical line represents a mean difference of zero or no effect. Squares located on the left side of this line represent studies showing an effect in the group treated with PGF ${ }_{2 \alpha}$, whereas squares located on the right side of this line indicate an effect found in the control group. Study or subgroup refers to the first author and year of the publication. Heterogeneity is quantified by between-studies variance $\left(\mathrm{Tau}^{2}\right)$, ratio of true heterogeneity to total observed variation $\left(I^{2}\right), \mathrm{Chi}^{2}$ and expected variation (df), and the respective $P$-values. Color version available online. 
quality criteria, such as blinding or randomization. Because trials of lower quality may show lower precision of the treatment effect estimate but higher treatment effects (Lam and Kennedy, 2005; Willich, 2006), we might argue whether weighting based merely on sample size is appropriate. Although the randomized trials by LeBlanc (2003) and Dubuc et al. (2011) were as heavily weighted as the 2 nonrandomized trials conducted by Mejía and Lacau-Mengido (2005), we decided to exclude only the latter trials in the course of sensitivity analysis. By using this approach, we simultaneously investigated the possible impact of large-weight and low-quality studies on the summary estimated effect obtained from the meta-analysis.

Concerning the investigation of potential publication bias, results did not differ considerably from those found in the prior meta-analysis. Publication bias for trials re-
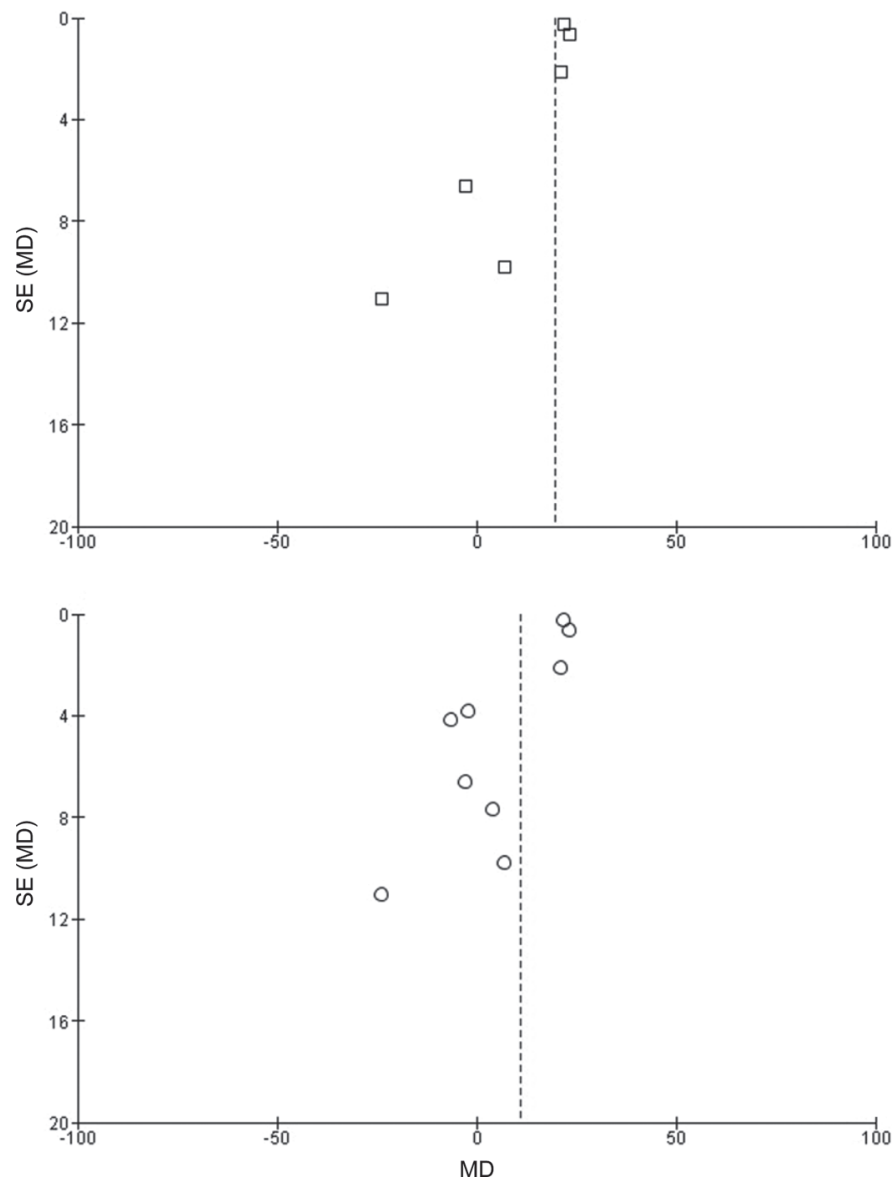

Figure 4. Funnel plot of $\mathrm{PGF}_{2 \alpha}$ effect on calving to conception interval for assessing publication bias. Comparison of the outcome of the initial meta-analysis (Haimerl et al., 2013; $\mathrm{n}=6$, top) and the updated meta-analysis $(\mathrm{n}=9$, bottom $) . \mathrm{MD}=$ mean difference; $\mathrm{SE}$ of $\mathrm{MD}=$ standard error of the standardized mean difference. The vertical line represents the mean effect size. Publication bias may be present if there is an unequal number of studies (particularly smaller weight studies) on one side of the horizontal line. porting CCI, however, was even more pronounced after updating the meta-analysis (Figure 4). This suggests that studies with higher standard error (i.e., usually smaller studies), which reported a prolonging effect on CCI after a $\mathrm{PGF}_{2 \alpha}$ treatment, were less likely to be published.

Finally, we strongly support the suggestion to regularly update meta-analyses. The update of our meta-analysis now provides results that are based on approximately twice the number of included cows, albeit without a substantial change in the overall outcome. With such updates, information with the highest level of evidence (Arlt et al., 2017) becomes available in a current form, can be incorporated in best practice recommendations, and might also stimulate further research. This is true even if an update adds only a relatively small number of recent trials. In relevant fields of veterinary medicine, we should consider every new result because it may significantly affect the current state of knowledge and thus change diagnostic or treatment recommendations.

The presented findings support the results of the prior meta-analysis. The number of trials published and their comparability are still limited. The recently conducted trials, however, were of better quality, including sufficient sample sizes and randomized allocation of animals. Reproductive performance after $\mathrm{PGF}_{2 \alpha}$ treatment of endometritic cows did not improve. Therefore, we do not recommend a treatment of bovine endometritis with $\mathrm{PGF}_{2 \alpha}$ as a means to improve reproductive performance.

\section{ACKNOWLEDGMENTS}

Special thanks to Stephen LeBlanc (University of Guelph, Ontario Veterinary College, Canada), Mauricio Giuliodori (National University of La Plata, Cátedra de Fisiología, Departamento de Ciencias Básicas Argentina), and Stefan Borchardt (Freie Universität Berlin, Clinic of Animal Reproduction, Germany) for sharing additional study data.

\section{REFERENCES}

Arlt, S., and W. Heuwieser. 2005. (Evidence based veterinary medicine). Dtsch. Tierarztl. Wochenschr. 112:146-148. [In German]

Arlt, S., W. Padberg, M. Drillich, and W. Heuwieser. 2009. Efficacy of homeopathic remedies as prophylaxis of bovine endometritis. J. Dairy Sci. 92:4945-4953. https://doi.org/10.3168/jds.2009-2142.

Arlt, S. P., P. Haimerl, and W. Heuwieser. 2017. Diagnostics and therapy in veterinary practice - How to stay up to date. Prakt. Tierarzt 98:56-60. https://doi.org/10.2376/0032-681X-17-07.

Borchardt, S., S. Ludwig, and W. Heuwieser. 2018. Randomized clinical trial to evaluate the efficacy of prostaglandin F2 $\alpha$ to treat purulent vaginal discharge in lactating dairy cows. J. Dairy Sci. (under review). https://doi.org/10.3168/jds.2018-14765.

Cochrane Collaboration. 2018. Aufgaben und Ziele von Cochrane. Accessed Apr. 11, 2018. http://www.cochrane.de/de/arbeitsgebiet. 
de Boer, M. W., S. J. LeBlanc, J. Dubuc, S. Meier, W. Heuwieser, S. Arlt, R. O. Gilbert, and S. McDougall. 2014. Invited review: Systematic review of diagnostic tests for reproductive-tract infection and inflammation in dairy cows. J. Dairy Sci. 97:3983-3999. https: //doi.org/10.3168/jds.2013-7450.

Dubuc, J., T. F. Duffield, K. E. Leslie, J. S. Walton, and S. J. LeBlanc. 2010. Definitions and diagnosis of postpartum endometritis in dairy cows. J. Dairy Sci. 93:5225-5233. https://doi.org/10 $.3168 /$ jds.2010-3428.

Dubuc, J., T. F. Duffield, K. E. Leslie, J. S. Walton, and S. J. Leblanc. 2011. Randomized clinical trial of antibiotic and prostaglandin treatments for uterine health and reproductive performance in dairy cows. J. Dairy Sci. 94:1325-1338. https://doi.org/10.3168/ jds.2010-3757.

Duffield, T. F., A. R. Rabiee, and I. J. Lean. 2008. A meta-analysis of the impact of monensin in lactating dairy cattle. Part 1. Metabolic effects. J. Dairy Sci. 91:1334-1346. https://doi.org/10.3168/ jds.2007-0607.

Feldmann, M., S. T. G. Emming, and M. Hoedemaker. 2005. [Treatment of chronic bovine endometritis and factors for treatment success]. Dtsch. Tierarztl. Wochenschr. 112:10-16. [In German]

Giuliodori, M. J., M. Magnasco, R. P. Magnasco, I. M. Lacau-Mengido, and R. L. de la Sota. 2017. Purulent vaginal discharge in grazing dairy cows: Risk factors, reproductive performance, and prostaglandin F2alpha treatment. J. Dairy Sci. 100:3805-3815. https://doi.org/10.3168/jds.2016-11373.

Haimerl, P., S. Arlt, and W. Heuwieser. 2012. Evidence-based medicine: quality and comparability of clinical trials investigating the efficacy of prostaglandin $\mathrm{F}$ (2alpha) for the treatment of bovine endometritis. J. Dairy Res. 79:287-296. https://doi.org/10.1017/ S002202991200012X.

Haimerl, P., W. Heuwieser, and S. Arlt. 2013. Therapy of bovine endometritis with prostaglandin F2alpha: A meta-analysis. J. Dairy Sci. 96:2973-2987. https://doi.org/10.3168/jds.2012-6154.

Hedges, L. V., and I. Olkin. 1985. Statistical Methods for Meta-Analysis. Academic Press, New York, NY.

Higgins, J. P., S. G. Thompson, J. J. Deeks, and D. G. Altman. 2003. Measuring inconsistency in meta-analyses. BMJ 327:557-560. https://doi.org/10.1136/bmj.327.7414.557.

Hirsbrunner, G., H. W. Burkhardt, and A. Steiner. 2006. Effects of a single administration of prostaglandin F2alpha, or a combination of prostaglandin F2alpha and prostaglandin E2, or placebo on fertility variables in dairy cows $3-5$ weeks post partum, a randomized, double-blind clinical trial. Reprod. Biol. Endocrinol. 4:65. https://doi.org/10.1186/1477-7827-4-65.

Kasimanickam, R., T. F. Duffield, R. A. Foster, C. J. Gartley, K. E. Leslie, J. S. Walton, and W. H. Johnson. 2005. The effect of a sin- gle administration of cephapirin or cloprostenol on the reproductive performance of dairy cows with subclinical endometritis. Theriogenology 63:818-830. https://doi.org/10.1016/j.theriogenology 2004.05.002.

Kaufmann, T. B., S. Westermann, M. Drillich, J. Plontzke, and W. Heuwieser. 2010. Systemic antibiotic treatment of clinical endometritis in dairy cows with ceftiofur or two doses of cloprostenol in a 14-d interval. Anim. Reprod. Sci. 121:55-62. https://doi.org/10 .1016/j.anireprosci.2010.04.190.

Lam, R. W., and S. H. Kennedy. 2005. Using metaanalysis to evaluate evidence: practical tips and traps. Can. J. Psychiatry 50:167-174. https://doi.org/10.1177/070674370505000306.

LeBlanc, S. 2003. Field study of the diagnosis and treatment of clinical endometritis in dairy cattle. Cattle Pract. 11:255-261.

Madoz, L. V., I. Prunner, M. Jaureguiberry, C. C. Gelfert, R. L. de la Sota, M. J. Giuliodori, and M. Drillich. 2017. Application of a bacteriological on-farm test to reduce antimicrobial usage in dairy cows with purulent vaginal discharge. J. Dairy Sci. 100:3875-3882. https://doi.org/10.3168/jds.2016-11931.

McDougall, S., M. de Boer, C. Compton, and S. J. Leblanc. 2013 Clinical trial of treatment programs for purulent vaginal discharge in lactating dairy cattle in New Zealand. Theriogenology 79:1139 1145. https://doi.org/10.1016/j.theriogenology.2013.02.002.

Mejía, M. E., and I. M. Lacau-Mengido. 2005. Endometritis treatment with a PGF2alpha analog does not improve reproductive performance in a large dairy herd in Argentina. Theriogenology 63:12661276. https://doi.org/10.1016/j.theriogenology.2004.05.023.

Sheldon, I. M., J. Cronin, L. Goetze, G. Donofrio, and H. J. Schuberth. 2009. Defining postpartum uterine disease and the mechanisms of infection and immunity in the female reproductive tract in cattle. Biol. Reprod. 81:1025-1032. https://doi.org/10.1095/biolreprod .109.077370.

Sheldon, I. M., G. S. Lewis, S. LeBlanc, and R. O. Gilbert. 2006 Defining postpartum uterine disease in cattle. Theriogenology 65:1516-1530. https://doi.org/10.1016/j.theriogenology.2005.08 .021 .

Steffan, J., M. Agric, S. Adriamanga, and M. Thibier. 1984. Treatment of metritis with antibiotics or prostaglandin F2 alpha and influence of ovarian cyclicity in dairy cows. Am. J. Vet. Res. 45:1090-1094

Wagener, K., C. Gabler, and M. Drillich. 2017. A review of the ongoing discussion about definition, diagnosis and pathomechanism of subclinical endometritis in dairy cows. Theriogenology 94:21-30. https://doi.org/10.1016/j.theriogenology.2017.02.005.

Willich, S. 2006. Randomisierte kontrollierte Studien-Pragmatische Ansätze erforderlich. Dtsch. Arztebl. 103:2524-2529. 